\title{
Symptomatic Postoperative Spinal Subdural Hematoma Following Posterior Lumbar Spinous Process-Splitting Decompression Surgery for Lumbar Spinal Canal Stenosis: A Case Report
}

\author{
Keitaro Ito ${ }^{1)}$, Nobuyuki Fujita ${ }^{122}$, Satoshi Suzuki ${ }^{1)}$, Satoshi Nori ${ }^{1)}$, Osahiko Tsuji ${ }^{1}$, Narihito Nagoshi ${ }^{1)}$, Eijiro Okada ${ }^{1)}$, \\ Mitsuru Yagi ${ }^{1)}$, Kota Watanabe ${ }^{1)}$, Masaya Nakamura ${ }^{1)}$ and Morio Matsumoto ${ }^{1)}$ \\ 1) Department of Orthopedic Surgery, School of Medicine, Keio University, Tokyo, Japan \\ 2) Department of Orthopedic Surgery, School of Medicine, Fujita Health University, Aichi, Japan
}

\begin{abstract}
Keywords:
lumbar spinal canal stenosis, postoperative spinal subdural hematoma, decompression surgery

Spine Surg Relat Res 2021; 5(2): 117-119

dx.doi.org/10.22603/ssrr.2020-0082
\end{abstract}

Posterior lumbar spinous process-splitting decompression surgery for lumbar spinal canal stenosis (LSS) is a wellestablished procedure with a relatively low risk of complications ${ }^{1)}$. However, serious complications, such as surgical site infections and symptomatic postoperative spinal epidural hematomas, occasionally occur and require prolonged hospitalization or surgical intervention ${ }^{2,3}$. Among the serious complications, symptomatic postoperative spinal subdural hematoma (PSSH) following lumbar surgery is extremely rare. We present the case of a patient with symptomatic PSSH following posterior lumbar spinous process-splitting decompression surgery for LSS.

A 79-year-old man diagnosed with LSS consulted our hospital for surgery. The patient presented with low back pain, bilateral leg pain, and intermittent claudication. He had been treated for lung cancer but had no other medical history. His blood test results, including APTT, PT, and platelet count, were normal. Lumbar magnetic resonance imaging (MRI) showed LSS at L2/3, 3/4, and 4/5 (Fig. 1). We performed posterior lumbar spinous process-splitting decompression surgery at the L2-5 level. The operative time was $83 \mathrm{~min}$, and there was no considerable blood loss as well as no unusual events during the surgery. The postoperative epidural suction drain was removed on the second postoperative day, after which his neurological symptoms improved. However, on the fifth postoperative day, his severe right leg pain recurred. Postoperative lumbar MRI showed no disk herniation or spinal epidural hematoma, but the presence of mild PSSH (Fig. 1). The patient's condition, in- cluding the Numerical Rating Scale score of right leg pain, was monitored, but severe pain persisted (Fig. 2). On the $14^{\text {th }}$ postoperative day, revision surgery was performed to confirm the diagnosis. Intraoperative findings showed no disk herniation, epidural hematoma, or nerve incarceration, but a subdural hematoma was observed (Fig. 3A); however, it did not show strong compression to the dura mater or nerve roots. An incision of the dura mater released yellow serous fluid (Fig. 3B). The arachnoid was intact (Fig. 3C). His symptoms dramatically improved, and his Numerical Rating Scale score of pain was 2 at discharge (Fig. 2). At postoperative 1 year, the patient continues to have no complaints of symptoms.

Our literature review found eight cases of symptomatic acute to subacute PSSH that occurred after posterior lumbar surgery $^{4-9)}$ (Table 1). Unintentional dural tear during surgery was reported to be involved in symptomatic $\mathrm{PSSH}^{4,5)}$; however, no intraoperative dural tears were observed in our case. We speculate that surgery-related traumatic manipulation on the dura mater may have damaged the subdural vascular structures and caused the hematoma ${ }^{5,6,8,9}$. Gehri et al. first reported that in PSSH, lumbar axial MRI shows semilunar fluid collection under the dura mater ${ }^{4)}$. Unlike postoperative spinal epidural hematomas, PSSH does not clearly show compression of the cauda equina or nerve root on MRI; therefore, the cause of neurological symptoms is unknown. Considering the rapid improvement of symptoms after removal of the hematoma in our case, the biochemical mediators included in the hematoma may have caused the neuro- 


\section{Preoperative lumbar spine T2-weighted MRI}
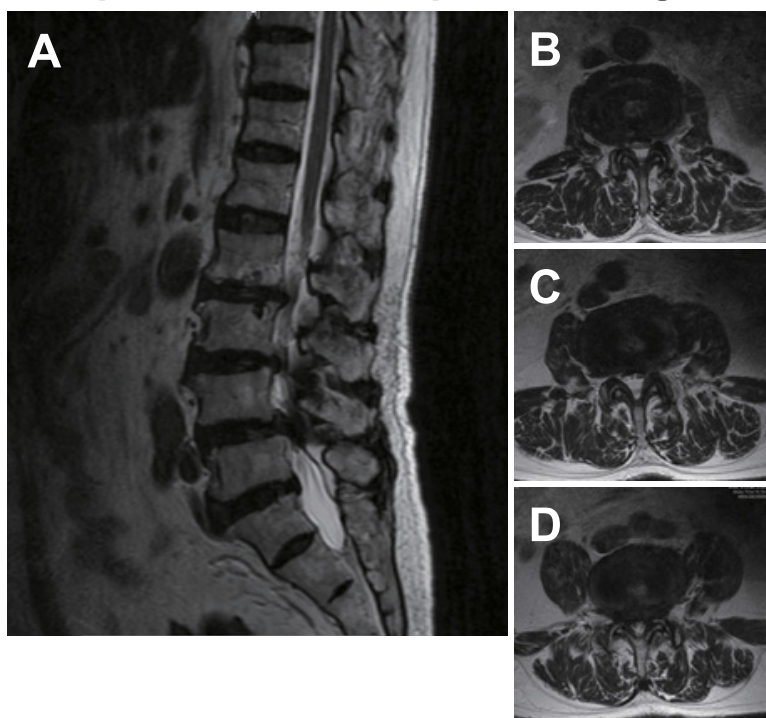

Postoperative lumbar spine T2-weighted MRI

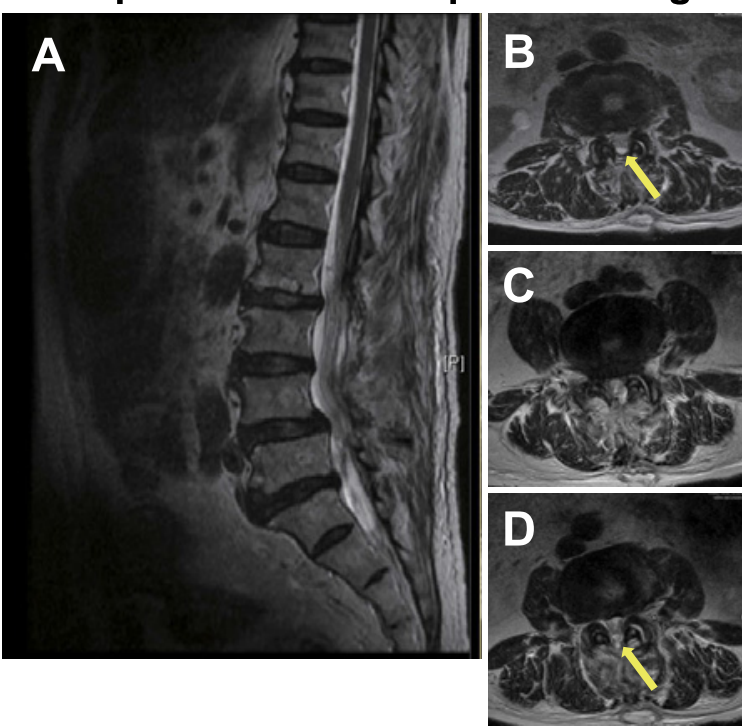

Figure 1. Pre- (top) and postoperative (bottom) lumbar spine T2-weighted magnetic resonance imaging on sagittal view (A) and axial view at L2/3 (B), L3/4 (C), and L4/5 (D). Yellow arrows suggest a subdural hematoma.

logical symptoms ${ }^{10)}$. Both conservative and surgical successful treatments for symptomatic PSSH have been reported ${ }^{4-9)}$. In our case, the patient's postoperative symptoms, including leg pain, did not improve after 1 week of observation; however, drainage through a dural incision was effective. Therefore, hematoma evacuation should be considered in patients with symptomatic PSSH for whom conservative therapy does not relieve the neurological symptoms. Although symptomatic PSSH is much less common than postoperative spinal epidural hematoma or surgical site infection, it should be considered as a possible complication of posterior lumbar spinous process-splitting decompression surgery for LSS.

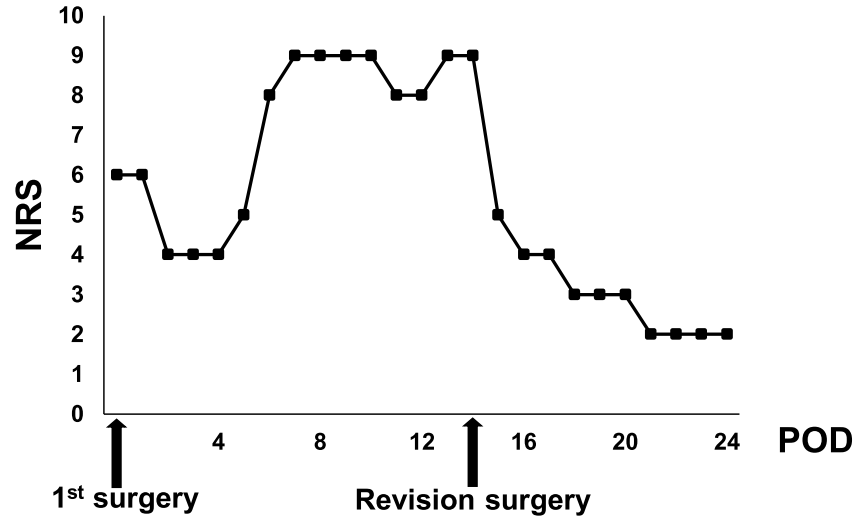

Figure 2. Postoperative Numerical Rating Scale scores of pain. The horizontal axis indicates postoperative day (POD).
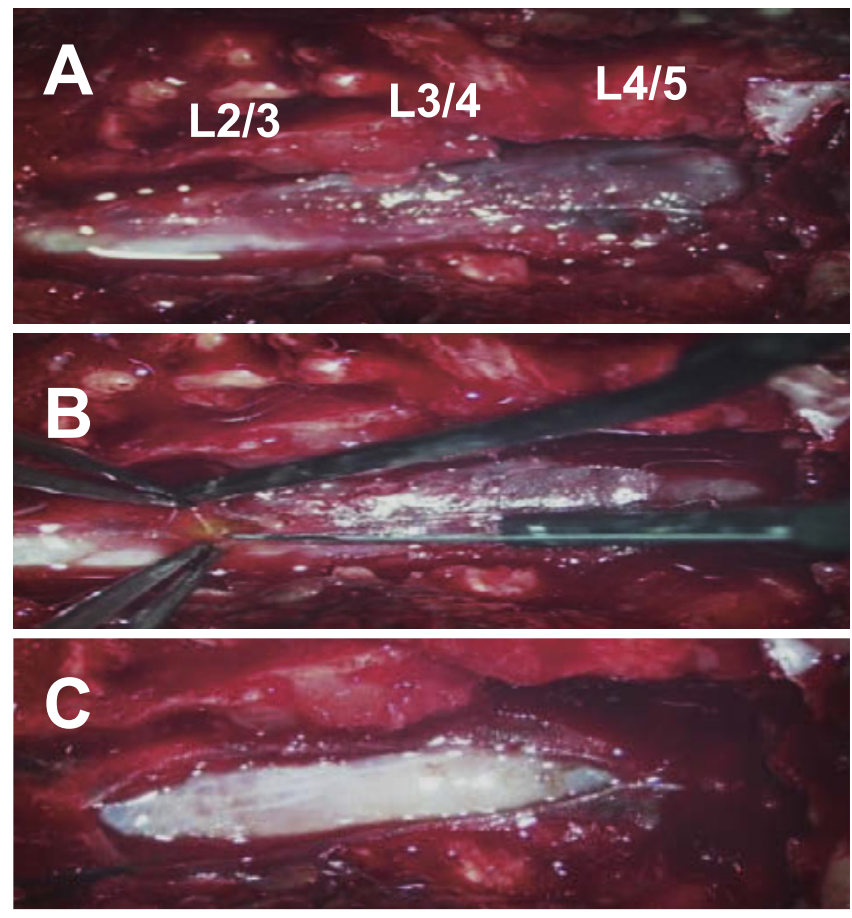

Figure 3. Intraoperative findings of the second surgery. Pre(A), intra- (B), and post- (C) incision of the dura mater.

Conflicts of Interest: The authors declare that there are no relevant conflicts of interest.

Ethical Approval: This study was approved by the Keio University Hospital Ethics Committee (approval number, 20110141).

Author Contributions: Conception and design: Nobuyuki Fujita, Kota Watanabe.

Acquisition of data: Keitaro Ito.

Interpretation of data: Satoshi Nori, Satoshi Suzuki, Osahiko Tsuji, Narihito Nagoshi, Eijiro Okada, Mitsuru Yagi, Kota Watanabe, Masaya Nakamura, Morio Matsumoto.

Study supervision: Kota Watanabe, Masaya Nakamura, 
Table 1. Previously Reported Cases of Symptomatic Postoperative Spinal Subdural Hematoma.

\begin{tabular}{|c|c|c|c|c|c|c|c|c|c|c|c|c|}
\hline & Age & Sex & Disease & Level & Surgery & $\begin{array}{l}\text { Dural } \\
\text { tear }\end{array}$ & $\begin{array}{l}\text { Occur- } \\
\text { rence } \\
\text { sites }\end{array}$ & Treatment & $\begin{array}{l}\text { Number of } \\
\text { PODs of } \\
\text { revision } \\
\text { surgery }\end{array}$ & $\begin{array}{c}\text { Intraoperative } \\
\text { characteristics } \\
\text { of PSSH }\end{array}$ & Outcome & $\begin{array}{l}\text { Refer- } \\
\text { ence }\end{array}$ \\
\hline 1 & 77 & M & LDH & $\mathrm{L} 5 / \mathrm{S} 1$ & Discectomy & + & Dorsal & Surgery & Unknown & $\begin{array}{l}\text { Xanthochromic } \\
\text { fluid + clots }\end{array}$ & Partial recovery & 4 \\
\hline 2 & 68 & M & LSS & L3-S1 & PLIF & - & Dorsal & Conservative therapy & & & Complete recovery & 5 \\
\hline 3 & 63 & M & LDH & $\mathrm{L} 3 / 4$ & Discectomy & + & $\begin{array}{c}\text { Dorsal + } \\
\text { ventral }\end{array}$ & Surgery & 3 days & Unknown & Complete recovery & 5 \\
\hline 4 & 59 & M & LSS & L3-S1 & PLIF & - & Dorsal & Surgery & 6 days & $\begin{array}{l}\text { Xanthochromic } \\
\text { fluid }\end{array}$ & Partial recovery & 6 \\
\hline 5 & 48 & M & DS & $\mathrm{L} 4 / 5$ & PLIF & Unclear & Dorsal & Conservative therapy & & & Complete recovery & 7 \\
\hline 6 & 76 & M & SS & L5 & PLIF & Unclear & Dorsal & Conservative therapy & & & Complete recovery & 7 \\
\hline 7 & 76 & M & SS & $\mathrm{L} 5 / \mathrm{S} 1$ & PLIF & - & Dorsal & Conservative therapy & & & Complete recovery & 8 \\
\hline 8 & 76 & M & LSS & L3-5 & $\begin{array}{l}\text { Laminecto- } \\
\text { my }\end{array}$ & - & Dorsal & Surgery & Unknown & $\begin{array}{l}\text { Xanthochromic } \\
\text { fluid }\end{array}$ & Complete recovery & 9 \\
\hline
\end{tabular}

LDH, lumbar disc herniation; DS, degenerative spondylolisthesis; SS, spondylolytic spondylolisthesis; LSS, lumbar spinal canal stenosis; PLIF, posterior lumbar interbody fusion; PODs, postoperative days; PSSH, postoperative spinal subdural hematoma

\section{Morio Matsumoto.}

Drafting the manuscript: Keitaro Ito, Nobuyuki Fujita.

Critically revising the manuscript: Satoshi Nori, Satoshi Suzuki, Osahiko Tsuji, Narihito Nagoshi, Eijiro Okada, Mitsuru Yagi, Kota Watanabe, Masaya Nakamura, Morio Matsumoto.

The final version of the manuscript was approved by all the authors.

Informed Consent: Informed consent was obtained by a participant in this study.

\section{References}

1. Watanabe K, Hosoya $T$, Shiraishi $T$, et al. Lumbar spinous process-splitting laminectomy for lumbar canal stenosis. Neurosurg Spine. 2005;3(5):405-8.

2. Ninomiya K, Fujita N, Hosogane N, et al. Presence of Modic type 1 change increases risk of postoperative pyogenic discitis following decompression surgery for lumbar canal stenosis. J Orthop Sci. 2017;22(6):988-93.

3. Fujita N, Michikawa T, Yagi M, et al. Impact of lumbar hypolordosis on the incidence of symptomatic postoperative spinal epidural hematoma after decompression surgery for lumbar spinal canal stenosis. Eur Spine J. 2019;28(1):87-93.
4. Gehri R, Zanetti M, Boos N. Subacute subdural hematoma complicating lumbar microdiscectomy. J Bone Joint Surg Br. 2000;82 (7):1042-5.

5. Lykissas MG, Aichmair A, Herzog RJ, et al. Spinal subdural hematoma following lumbar decompressive surgery: a report of two cases. Wien Klin Wochenschr. 2015;127(1-2):71-4.

6. Chang KC, Samartzis D, Luk KD, et al. Acute spinal subdural hematoma complicating lumbar decompressive surgery. Evid Based Spine Care J. 2012;3(1):57-62.

7. Sakai T, Sairyo K, Bhatia NN, et al. MRI changes of the spinal subdural space after lumbar spine surgeries: Report of Two Cases. Asian Spine J. 2011;5(4):262-6.

8. Gakhar H, Bommireddy R, Klezl Z, et al. Spinal subdural hematoma as a complication of spinal surgery: can it happen without dural tear?. Eur Spine J. 2013;22(3):346-9.

9. Boe CC, Freedman BA, Kumar R, et al. Spinal subdural hematoma: a rare case of spinal subdural hematoma complicating routine, minimally invasive lumbar discectomy and decompression and relevant literature review. J Spine Surgery. 2017;3(1):112-8.

10. Qureshi AI, Mendelow AD, Hanley DF. Intracerebral haemorrhage. Lancet. 2009;373(9675):1632-44.

Spine Surgery and Related Research is an Open Access journal distributed under the Creative Commons Attribution-NonCommercial-NoDerivatives 4.0 International License. To view the details of this license, please visit (https://creativeco mmons.org/licenses/by-nc-nd/4.0/). 